\title{
Voltaire, Oeuvres de 1750-1752/Writings of 1750-1752
}

\section{Franco Piva}

\section{(2) OpenEdition}

\section{Journals}

\section{Édition électronique}

URL : http://journals.openedition.org/studifrancesi/8919

DOI : 10.4000/studifrancesi.8919

ISSN : 2427-5856

\section{Éditeur}

Rosenberg \& Sellier

\section{Édition imprimée}

Date de publication : 1 octobre 2008

Pagination : 457

ISSN : 0039-2944

\section{Référence électronique}

Franco Piva, « Voltaire, Oeuvres de 1750-1752/Writings of 1750-1752 », Studi Francesi [En ligne], 155 (LII I II) | 2008, mis en ligne le 30 novembre 2015, consulté le 08 janvier 2021. URL : http://

journals.openedition.org/studifrancesi/8919; DOI : https://doi.org/10.4000/studifrancesi.8919

Ce document a été généré automatiquement le 8 janvier 2021.

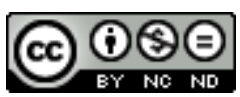

Studi Francesi è distribuita con Licenza Creative Commons Attribuzione - Non commerciale - Non opere derivate 4.0 Internazionale. 


\title{
Voltaire, Oeuvres de 1750-1752/ Writings of 1750-1752
}

\author{
Franco Piva
}

\section{RÉFÉRENCE}

VOLTAIRE, Oeuvres de 1750-1752/Writings of 1750-1752, t. II, Oxford, Voltaire Foundation («Les CEuvres complètes de Voltaire», 32B), 2007, pp. XV+374.

1 Le texte le plus important de ce volume des Euvres complètes de Voltaire est sans aucun doute représenté par le Poème sur la loi naturelle. Conçu à la fin de 1750 ou au début de 1751, après et à la suite de la lecture de l'Anti-Sénèque ou le souverain bien de La Mettrie, dont les vues profondément matérialistes avaient fort choqué Voltaire, le Poème sur la loi naturelle, composé essentiellement au cours de l'année 1751, ne parut en librairie qu'en 1756, avec le Poème sur le désastre de Lisbonne. C'est dire les soins que Voltaire apporta à cet ouvrage, qui a marqué une étape très importante dans sa vie intellectuelle, et dans l'évolutions même de ses idées. Ainsi que le montrent H. T. Mason et Thomas Wynn dans leur Introduction, Voltaire puisa avant tout à l'Essay on Man de Pope, sans oublier cependant le second volume des Characteristics de Shaftesbury, en particulier pour ses recherches sur la vertu, et même La Religion de Louis Racine, dans la mesure où, «despite their many differences», Voltaire était, comme Racine, "concerned to demonstrate the existence of God». Le Poème, qui connut un énorme succès auprès $\mathrm{du}$ public, suscita les réactions violentes de la partie la plus conservatrice, mais fut relativement bien reçu par la partie la plus éclairée qui y vit «a profession de foi, not unlike certain aspects of that which Rousseau's Vicaire Savoyard will pronounce some years later", capable en tout cas de contrecarrer positivement l'athéisme de La Mettrie (pp. 1-96).

2 Outre L'art de la guerre de Frédéric de Prusse, avec les abondantes notes que Voltaire, à qui le «philosophe de Sans Souci» avait envoyé le poème dans sa première mouture afin qu'il y apporte ses corrections et ses observations, y a faites, et qui est ici proposé dans 
le texte que Th. Besterman avait publié dans le deuxième volume des Studies on Voltaire en 1956 (pp. 97-215), le volume comprend la Défense de Milord Bolingbroke, par le Docteur Good Natur'd Wellvisher, chapelain du comte de Chesterfield, éditée par Roland Mortier (pp. 217-249), dans laquelle Voltaire défend vigoureusement Milord Bolingbroke contre les attaques dont le philosophe anglais fut l'objet après sa mort, surtout pour sa manière de concevoir l'histoire, et l'histoire sainte tout particulièrement, et quelques écrits liés aux polémiques suscitées par la dure prise de position de Voltaire contre Maupertuis à l'époque de son séjour à Berlin: les Mémoires sur La Beaumelle, édités par Claude Lauriol (pp. 251-274); l'Extrait de la Bibliothèque raisonnée, comprenant un très vénimeux compte rendu des Euvres de M. de Maupertuis, édité par David Beeson (pp. 275-312) et, en Appendice, Le Tombeau de la Sorbonne, un écrit lié à l'affaire de Prades, que certains indices portent à attribuer à Voltaire, et dans lequel Voltaire a en tout cas mis abondamment les mains (édité par Olivier Ferret, pp. 313-359). Le volume, préparé avec les soins auxquels les éditeurs des Euvres complètes de Voltaire nous ont habitués, est clos par l'Index des ouvrages cités et des noms. 